\title{
Ternary Liquid Equilibrium for Eugenol + Tert- Butanol + Water and Eugenol + 1-Octanol + Water System At 303.15 K and Atmospheric Pressure
}

\author{
Retno Kumala $^{1 *}$, Gede Wibawa ${ }^{1}$, Kuswandi ${ }^{1}$ \\ ${ }^{I}$ Department of Chemical Engineering, Sepuluh Nopember Institute of Technology (ITS), Kampus ITS Sukoillo Sura- \\ baya 60111, Indonesia. \\ *Corresponding author.Email: retnokhs@gmail.com
}

\begin{abstract}
The objective of this work was to determine ternary liquid-liquid equilibrium for eugenol + tert-butanol + water and eugenol + 1-octanol + water systems at $303.15 \mathrm{~K}$ and atmospheric pressure. The experimental apparatus was $25 \mathrm{~mL}$ equilibrium cell equipped jacketed water connected to water bath to maintain equilibrium temperature at constant value. The procedure of this experiment was conducted by inserting mixture of eugenol + tert-butanol + water and eugenol + 1-octanol + water systems at certain composition into equilibrium cell. The solution was stirred for 4 hours and then was allowed for 20 hours in order to separate aqueous and organic phases completely. The equilibrium compositions of each phase were analysed using gas chromatography. The experimental data obtained in this work were correlated with NRTL and UNIQUAC models giving root standard mean deviation of $1.1 \%$ and $1.5 \%$, respectively for eugenol + tert-butanol + water system and that of $2.8 \%$ and $3.1 \%$, respectively for eugenol +1 -octanol + water system. 1-octanol which has better capability than tert-butanol as a solvent for eugenol.
\end{abstract}

Keywords: Ternary liquid, equilibrium, LLE, NRTL, UNIQUAC

\section{INTRODUCTION}

Indonesia is an agricultural country with a variety of abundant biological resources. Clove is a plant that grows a lot in Indonesia. Indonesia is one of the suppliers of clove production in the world, which is $63 \%$ [1]. These cloves are processed into clove oil which is one of the types of essential oils that has many uses, including aromatherapy with a distinctive fragrance, natural pesticides, sunscreen, food additives and in the cigarette industry. Clove flowers, leaves, and stems can be extracted to produce clove oil. The oil contained in the flower parts is $17-18 \%$ while in the leaves it is around $2-3 \%$ of the total clove oil [2]. Clove oil has a complex composition of chemical compounds, one of which is a terpene compound, namely $\beta$-caryophyllene. $\beta$ caryophyllene has the characteristics of a colourless liquid, has a distinctive aroma, and is often used in the pharmaceutical industry. $\beta$-caryophyllene in clove oil contains as much as $10 \%$. The largest component are eugenol with levels $70-80 \%$ [1]. Because $\beta$ - caryophyllene and eugenol have similar characteristic so separation each component must do it for get pure component.

The separation process of terpene from oil called deterpenisation which is aimed to improve flavor and aroma, increase solubility, and maintain stability during storage [2]. The process of deterpenisation can be done by several methods, such as conventional methods (vacuum and steam distillation) and extraction with organic solvent. However, in the distillation process only a portion of the terpene component is picked up and this process occasionally causes oil degradation due to heating [5]. Therefore, the extraction method is more widely used because it can avoid the occurrence of degradation [4].

In the extraction process, solvent is an important factor that must be considered based on its properties such as polarity, volatility, and toxicity. Future applications in the fields of food, cosmetics and pharmaceuticals are required to use alcohol [5]. The use of alcohol 
as a solvent for extraction has several advantages, including (1) alcohol having high solubility in water; (2) non-toxic; (3) increasing the scent of the mixture; (4) the oxidation reaction is reduced in the presence of alcohol; (5) solvent dilute of alcohol is so selective that can dissolve terpene, but slightly dissolved eugenol [6]. As one type of alcohol, methanol can be used as a solvent, but it turns out that methanol is corrosive in that it can damage the extraction column. There are several studies that develop ethanol as a solvent, but ethanol is rarely used as a solvent in beverage production. This is because the selling price of ethanol is more expensive as an alcoholic beverage than as a solvent. Therefore, this research was conducted to find other solvents from other alcohol compounds that have a lower risk of deviation. One of them is tert-butanol and 1-octanol. tertbutanol and 1-octanol dissolved in various ranges of non-polar compounds. It also vaporizes rapidly and is relatively non-toxic so it is well used as a solvent especially for dissolving oil.

In the extraction process, thermodynamic properties of liquid-liquid phase equilibrium are required to design the separation process equipment. Equilibrium phase is a static state where there is no macroscopic change in the properties of a system that is affected by time. When the phases are not condition in equilibrium, there will be mass transfer between phases where the transfer rate of each component depends on the driving force, in this case the magnitude of the system deviation from an equilibrium. Thus the knowledge of liquid-liquid equilibrium for such systems are necessary to rational design and determining optimum process conditions of the separation process. In addition, the equilibrium data is important to develop solution theory [7]. In this work, the experiment was continued to determine ternary liquid-liquid equilibrium for other system that is eugenol + tert-butanol + water and eugenol +1 -octanol + water systems. The data were correlated with NRTL and UNIQUAC models, to confirm the consistency of experimental was used the Bachman-Brown correlation.

\section{METHODS}

\subsection{Materials}

Eugenol with $99.9 \%$ purity was obtained from PT. Indesso Niagatama. 1-tert-butanol and 1-octanol with $99.8 \%$ purity were obtained from MERCK, and aquabidestilata was obtained from PT. Ikapharmindo Putramas. The purity of the materials were checked using Gas Chromatography. All materials used in this experiment are pure compounds. Detail specification of materials used in this work included UNIQUAC parameters of pure properties are presented in Table 1.

\subsection{Apparatus and Procedure}

The equilibrium cell is equipped with a magnetic stirrer and a jacket to maintain the temperature of equilibrium cell at desired temperature by circulating water from water bath as heating medium. The ternary mixture at certain composition was inserted to the equilibrium cell and stirred at a temperature of $303.15 \mathrm{~K}$ and atmospheric pressure for 4 hours, then the mixture was allowed to separate into organic and aqueous phase for about 20 hours.

The samples of each phase was collected and these compositions were analyzed using GC with TCD detector using RTX-5 column. Helium was used as carrier gas.

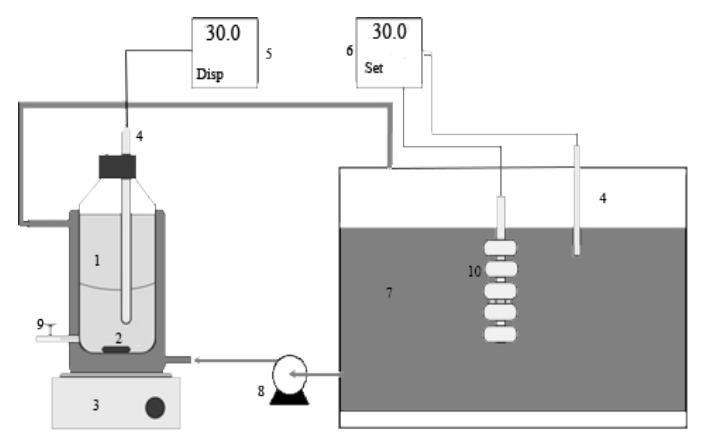

Figure 1. Schematic diagram of the equipment used for the experiment.

1 Jacketed equilibrium cell

2 stir bar

3 Dragon Lab MS-H280-Pro stirrer

4 RTD Pt100

5 Temperature display

6 Temperature display

7 PolyScience 9012 water bath

8 circulation pump

9 sampling port

10 heater.

\section{RESULTS AND DISCUSSION}

The correlations Bachman-Brown is used to reliability of the experimental data [9]. The BachmanBrown correlation is

$$
\frac{x_{1}^{I}}{x_{3}^{I I}}=A x_{1}^{I}+B
$$


Table 1. Experimental LLE data for eugenol (1) + alcohols (2) + water (3) systems at 303.15K.

\begin{tabular}{|c|c|c|c|c|c|c|c|}
\hline \multirow{2}{*}{ System } & \multicolumn{3}{|c|}{ Organic Phase (I) } & \multicolumn{3}{|c|}{ Aquous Phase (II) } & \multirow{2}{*}{$\mathrm{K}$} \\
\hline & $w_{1}$ & $w_{2}$ & $w_{3}$ & $w_{1}$ & $w_{2}$ & $w_{3}$ & \\
\hline \multirow{8}{*}{$\begin{array}{c}\text { Eugenol }+ \text { tert-butanol }+ \\
\text { water }\end{array}$} & 1.000 & 0.0000 & 0.0000 & 0.0055 & 0.0000 & 0.9945 & 181.79 \\
\hline & 0.9071 & 0.0881 & 0.0048 & 0.0050 & 0.0212 & 0.9737 & 179.95 \\
\hline & 0.8235 & 0.1649 & 0.0116 & 0.0053 & 0.0220 & 0.9727 & 154.27 \\
\hline & 0.7264 & 0.2535 & 0.0202 & 0.0055 & 0.0221 & 0.9725 & 133.24 \\
\hline & 0.6097 & 0.3638 & 0.0265 & 0.0055 & 0.0239 & 0.9706 & 110.58 \\
\hline & 0.6034 & 0.3660 & 0.0306 & 0.0054 & 0.0239 & 0.9707 & 112.25 \\
\hline & 0.4366 & 0.5087 & 0.0548 & 0.0054 & 0.0389 & 0.9558 & 81.35 \\
\hline & 0.0007 & 0.8776 & 0.1217 & 0.0051 & 0.0445 & 0.9503 & 0.14 \\
\hline \multirow{9}{*}{$\begin{array}{l}\text { Eugenol }+1 \text {-octanol + } \\
\text { water }\end{array}$} & 0.0171 & 0.9267 & 0.0563 & 0.0001 & 0.0001 & 0.9998 & 150.54 \\
\hline & 0.2085 & 0.7598 & 0.0316 & 0.0001 & 0.0001 & 0.9998 & 1838.57 \\
\hline & 0.3759 & 0.6036 & 0.0205 & 0.0001 & 0.0001 & 0.9998 & 3314.46 \\
\hline & 0.5233 & 0.4666 & 0.0101 & 0.0001 & 0.0001 & 0.9998 & 4613.71 \\
\hline & 0.6526 & 0.3411 & 0.0064 & 0.0001 & 0.0001 & 0.9998 & 5753.66 \\
\hline & 0.7588 & 0.2378 & 0.0034 & 0.0001 & 0.0001 & 0.9998 & 6690.49 \\
\hline & 0.8523 & 0.1444 & 0.0032 & 0.0001 & 0.0001 & 0.9998 & 7514.98 \\
\hline & 0.9303 & 0.0656 & 0.0042 & 0.0001 & 0.0001 & 0.9998 & 8201.99 \\
\hline & 0.9946 & 0.0000 & 0.0054 & 0.0001 & 0.0001 & 0.9998 & 8769.66 \\
\hline
\end{tabular}

where $\mathrm{A}$ and $\mathrm{B}$ are the Bachman-Brown correlation parameters, $x_{1}^{I}$ is the mole fraction of eugenol in the organic phase and $x_{3}^{I I}$ is the mole fraction of water in the aqueous phase.

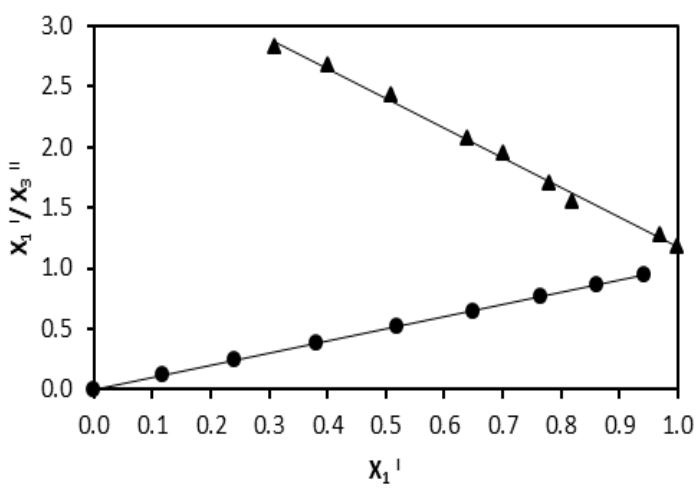

Figure 2. The Bachman-Brown correlation for eugenol + alcohols + water systems at $303.15 \mathrm{~K}$; tertbutanol; 1-octanol.

The NRTL equation with 3 parameters was proposed by Renon and Prausnitz [10]. This equation is derived based on the concept of local composition pioneered by Wilson [11]. This NRTL equation can be used for partially dissolved systems as well as for perfectly soluble systems. This equation can be used extensively in vaporliquid equilibria (VLE) and LLE for different types of substances, eg mixtures of saturated hydrocarbons and polar species, mixtures of non-polar compounds, mixtures of air and polar species, and mixtures of alcohols with mixed non-polar species. The NRTL model for multicomponent systems ia as follows:

$$
\begin{aligned}
& \ln \gamma_{i}=\frac{\sum_{j=1}^{n} \tau_{j i} G_{j i} x_{j}}{\sum_{k=1}^{n} G_{k i} x_{k}}+\sum_{j=1}^{n} \frac{x_{j} G_{i j}}{\sum_{k=1}^{n} G_{k j} x_{k}}\left(\tau_{i j}-\right. \\
& \left.\sum_{k=1}^{n} \frac{x_{k} \tau_{k j} G_{k j}}{\sum_{k=1}^{n} G_{k j} x_{k}}\right) \\
& \tau_{j i}=\frac{g_{j i}-g_{i i}}{R T} \\
& G_{j i}=\exp \left(-\alpha_{j i} \tau_{j i}\right) \\
& \tau_{i i}=\tau_{j j}=0 \\
& G_{i i}=G_{j j}=1
\end{aligned}
$$

Table 2. The Bachman-Brown correlation for euge$\mathrm{nol}+$ alcohols + water systems at $303.15 \mathrm{~K}$.

\begin{tabular}{|c|c|c|c|}
\hline Correlation & & $\begin{array}{c}\text { Tert- } \\
\text { Butanol }\end{array}$ & 1-Octanol \\
\hline Bachman- & A & -2.4503 & 1 \\
\hline
\end{tabular}




\begin{tabular}{|c|c|c|c|c|}
\hline \multirow[t]{2}{*}{ Brown } & B & 3.6265 & 0 & \multirow{2}{*}{$\begin{array}{r}\mathrm{l}_{\mathrm{j}}=\frac{\mathrm{z}}{2}\left(\mathrm{r}_{\mathrm{j}}-\mathrm{q}_{\mathrm{j}}\right)-\left(\mathrm{r}_{\mathrm{j}}-1\right) \\
\left(\left(u_{j i}-u_{i i}\right)\right)\end{array}$} \\
\hline & $\mathrm{R}^{2}$ & 0.9955 & 1 & \\
\hline
\end{tabular}

Table 3. The NRTL and UNIQUAC model parameters for eugenol (1) + alcohols (2) + water (3) systems at $303.15 \mathrm{~K}$.

\begin{tabular}{|c|c|c|c|c|c|}
\hline \multirow{2}{*}{ System } & \multicolumn{3}{|c|}{ NRTL parameters $(\mathrm{K})$} & \multirow{2}{*}{$\alpha_{i j}$} & \multirow{2}{*}{$\begin{array}{c}\text { RMSD } \\
(\%)\end{array}$} \\
\hline & $i-j$ & $\left(g_{i j}-g_{i i}\right) / R$ & $\left(g_{j i}-g_{j j}\right) / R$ & & \\
\hline \multirow{3}{*}{$\begin{array}{c}\text { eugenol +tert butanol } \\
+ \text { water }\end{array}$} & $1-2$ & 7723 & 5983 & 0.2 & \multirow{3}{*}{1.2} \\
\hline & $2-3$ & 4039 & 6123 & & \\
\hline & $1-3$ & -232 & 1691 & & \\
\hline \multirow{3}{*}{ eugenol + 1-octanol + water } & $1-2$ & 1528 & 1259 & 0.47 & \multirow{3}{*}{1.1} \\
\hline & $2-3$ & 15200 & 3680 & & \\
\hline & $1-3$ & 56.14 & 82.85 & & \\
\hline \multirow{2}{*}{ System } & \multicolumn{3}{|c|}{ UNIQUAC parameters (K) } & & \multirow{2}{*}{$\begin{array}{c}\text { RMSD } \\
(\%)\end{array}$} \\
\hline & $i-j$ & $\left(u_{i j}-u_{i i}\right) / R$ & $\left(u_{j i}-u_{j j}\right) / R$ & & \\
\hline \multirow{3}{*}{ eugenol + tert-butanol + water } & $1-2$ & -215.01 & 6152 & & \multirow{3}{*}{3.1} \\
\hline & $2-3$ & 121.31 & 1521 & & \\
\hline & $1-3$ & -57.63 & 421.4 & & \\
\hline \multirow{3}{*}{ eugenol + 1-octanol + water } & $1-2$ & -126.74 & 825.4 & & \multirow{3}{*}{4.3} \\
\hline & $2-3$ & 6070.8 & 2908 & & \\
\hline & $1-3$ & 299.8 & 1487 & & \\
\hline
\end{tabular}

The UNIQUAC equation was proposed by Abrams and Prausnitz [12]. This equation can also be used for soluble or partially soluble liquid systems. The UNIQUAC equation can be applied to organic liquid mixture.

The equation consists of two parts, the combinatorial part or the entropy effect comprising only pure component parameters to calculate the difference in shape and size of the molecule, as well as the residual or enthalpy effects that combine two binary parameters per pair of molecules to calculate molecular interactions.

$\ln \gamma_{i}=\ln \gamma_{i}{ }^{C}+\ln \gamma_{i}{ }^{R}$

Multicomponent system:

$\ln \gamma_{\mathrm{i}}^{\mathrm{c}}=\ln \frac{\varphi_{\mathrm{i}}}{\mathrm{x}_{\mathrm{i}}}+\frac{\mathrm{z}}{2} \mathrm{q}_{\mathrm{i}} \ln \frac{\vartheta_{\mathrm{i}}}{\varphi_{\mathrm{i}}}+\mathrm{l}_{\mathrm{i}}-\frac{\varphi_{\mathrm{i}}}{\mathrm{x}_{\mathrm{i}}} \sum_{\mathrm{j}}^{\mathrm{n}} \mathrm{x}_{\mathrm{j}} \mathrm{l}_{\mathrm{j}}$
$\ln \gamma_{\mathrm{i}}^{\mathrm{R}}=\mathrm{q}_{\mathrm{i}}\left[1-\ln \left(\sum_{\mathrm{j}}^{\mathrm{n}} \vartheta_{\mathrm{j}} \tau_{\mathrm{ji}}\right)-\sum_{\mathrm{j}}^{\mathrm{n}} \frac{\vartheta_{\mathrm{j}} \tau_{\mathrm{ij}}}{\sum_{\mathrm{k}}^{\mathrm{n}} \vartheta_{\mathrm{k}} \tau_{\mathrm{kj}}}\right]$

$\mathrm{z}=10$

$\mathrm{l}_{\mathrm{i}}=\frac{\mathrm{z}}{2}\left(\mathrm{r}_{\mathrm{i}}-\mathrm{q}_{\mathrm{i}}\right)-\left(\mathrm{r}_{\mathrm{i}}-1\right)$ $\tau_{i j}=\exp \left(-\frac{u_{i j}-u_{i i}}{R T}\right)$

$\tau_{i i}=\tau_{j j}=1$

Binary parameters of NRTL were fitted with experimental data by setting $\alpha=0.2-0.5$ [13]. The experimental data were treated based on isofugacity concept as follows:

$\left(x_{i} \gamma_{i}\right)^{I}=\left(x_{i} \gamma_{i}\right)^{I I}$

where the activity coefficient of component $i, \gamma_{i}$ were calculated using NRTL and UNIQUAC models. The root mean square deviation (RMSD) formula:

$\operatorname{RMSD}=\left[\frac{\sum_{i} \sum_{\alpha} \sum_{k}\left(x_{i k}^{\alpha(\exp )}-x_{i k}^{\alpha(c a l)}\right)^{2}}{2 \vartheta N}\right]^{1 / 2}$

where $\vartheta$ is the number of components and $\mathrm{N}$ is the number of tie-lines.

Comparison between the experimental data and calculated equilibrium compositions using both equations giving RSMD for three ternary systems less than $5 \%$ [14]. Therefore, correlation results presented by NRTL 
and UNIQUAC models are in a good agreement with the experimental data.

Both systems studied exhibit ternary diagram of type II behaviour in which there are two partially miscible substances as shown in Figure 3 and 4.

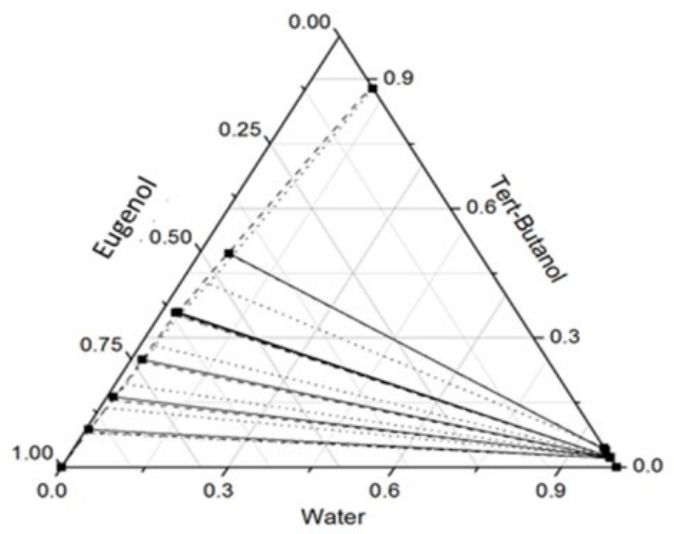

Figure 3. Ternary liquid-liquid equilibrium for eugenol + tert-butanol + water system at $303.15 \mathrm{~K}$ compared with (- - -) NRTL and (*) UNIQUAC equations

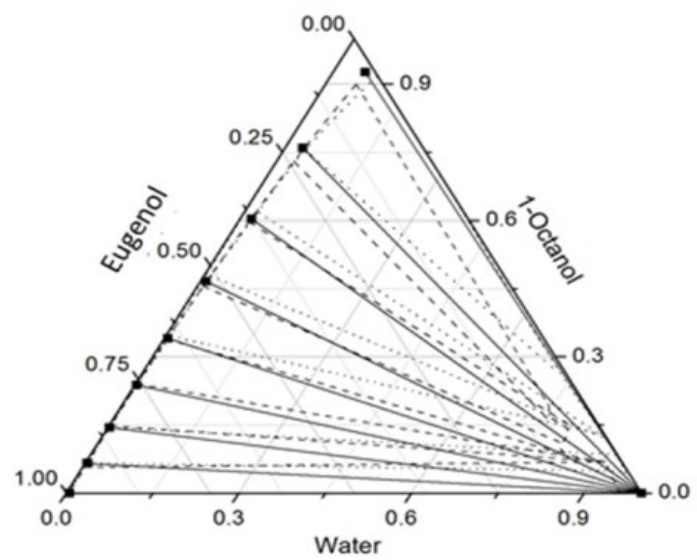

Figure 4. Ternary liquid-liquid equilibrium for eugenol +1 -octanol + water System at $303.15 \mathrm{~K}$ compared with (- - ) NRTL and ( . $)$ UNIQUAC equations.

Figure 3 shows the Solubility of the eugenol + tertbutanol + water system in accordance with the principle of polarity because eugenol has a non-polar tendency whereas tert-butanol has a non-polar tendency, thus eugenol is soluble with tert-butanol, while tert-butanol is not completely soluble with water and eugenol is insoluble (very little soluble) with water.

Figure 4 shows the Solubility of the eugenol +1 octanol + water system in accordance with the principle of polarity because eugenol has a non-polar tendency while ethanol has non polar properties, so eugenol is soluble in 1-octanol, whereas Octanol tends to dissolve with water (polar) and eugenol is sligtly soluble in water.

To understand extraction ability of alcohol (tertbutanol and 1-octanol), we can calculate distribution coefficient $\left(K_{l}\right)$ of eugenol with formula:

$K_{1}=\frac{w_{1}^{I I}}{w_{1}^{I}}$

Where $w_{1}^{I}$ and $w_{1}^{I I}$ were mass fraction of eugenol in water and alcohol phases, respectively [15]. Value from distribution coefficient $(\mathrm{K})$ given are Table 2 and Figure 5.

The figure shows the distribution coefficient $\left(K_{I}\right)$ of eugenol in tert-butanol and that in octanol solvents. As shown in the figure that $K_{I}$ is much larger in 1-octanol than in tert -butanol. Therefore, the capability of 1octanol was better than that of tert-butanol as a solvent for $\beta$ - eugenol since octanol has a more non-polar property compared with tert-butanol. As a result, the eugenol will be easier to distribute with 1-octanol molecules than with tert-butanol molecules.

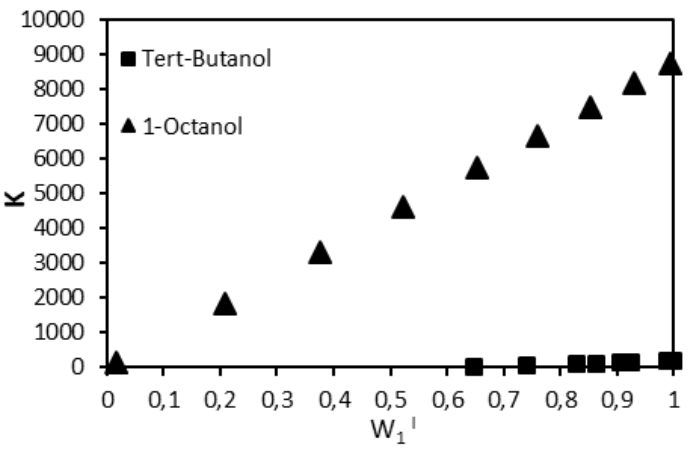

Figure 5. Coefficient Distribution.

A solubility principle is a substance which will be soluble only on the appropriate solvent. In other words, a polar substance dissolves in a polar solvent and a nonpolar element will dissolve in a non-polar solvent. This principle is known by the principle of like dissolve like [16].<smiles>CCCCCCC(C)C</smiles>

Figure 6. Structure molecule 1-octanol. 
The solubility behaviour may be described from the molecule structure of tert-butanol, 1-octanol and eugenol as shown in Figure 6, 7 and 8, respectively, where the polarity can be determined from the chemical structure.<smiles>CC(C)(C)O</smiles>

Figure 7. Structure molecule tert-butanol.<smiles>C=CCc1ccc(O)c(OC)c1</smiles>

Figure 8. Structure molecule eugenol

The first factor is the length of the carbon chain, the organic molecules that have a longer carbon chain number will have more non-polar properties compared to molecules that have shorter carbon chains, and the number of branches in organic molecules as well because molecular modelling has branches, then the molecules will have higher polarity properties with a structure that has no branches [17]. The second factor is the functional group, the functional group in a molecule determines the polarity of a molecule because there is a possibility of reaction between molecules then the atoms may interact each other in the functional group. Besides each functional group may cause a molecule to have special properties, the reactivity of this functional group determine its polarity, so the more reactive the functional group in a molecule the more polar the molecule will be [18]. The third factor is the hydrogen bond, the hydrogen bond in a molecule can be said to emit polarity because it has a molecule of hydrogen then the molecule will be easier to interact with other molecules that have atoms that can form hydrogen bonds, so that between molecules were hydrogen bond will occur [19]. The fourth factor is the steric effect between atoms between molecules, discard the steric effect between molecules that occur larger than the polarity of a molecule will be reduced so that the ability to interact / distributed with other molecules will increase as well [20]. The last factor of polarity of compound is dipole moment.

Table 4 presents total energy functional group, the dipole moment, RMS gradient and stearic effect values of each compound affected the solubility of solvent. In which eugenol has a very non polar character because the polarity value shown by dipole moment is zero, whereas 1-ocatnol has the dipole moment value lower than that of tert-butanol. So that, 1-octanol is more non polar compared with tert-butanol. Since water compound having the value of dipole moment more than 1 , water has strongly polar property. Therefore, eugenol is more soluble in 1-octanol than in that tert-butanol and water [22].

The capability of octanol is better than tert-butanol to solve eugenol because octanol has chemical structure similar to eugenol compared to tert-butanol. Figure 8 shows the eugenol molecule itself has a high non polar property due to the cyclo structure of the eugenol molecule and the presence of 2 double bonds (alkene groups) which cause the non-polar molecule of eugenol. The non-polar properties of octanol are much higher than tert-butanol due to several factors, ie. the number of carbon chains owned by octanol is longer than the number of carbon chains owned by tert-butanol, the structure of octanol which is an aliphatic chain that does not have a branch that steric effects that occur between atoms hydrogen in molecular octanol a lower energy than the steric effect that occurs between hydrogen atoms in the molecule tert-butanol wherein the molecule tertbutanol possessed two branches hydroxy. Besides, methyl branch causes the bonds between atoms is shorter, so that the steric effect that occurs will be larger (large an energy). eugenol would prefer a molecule that has lower a stericeffects, because the energy possessed by molecules tends to be small and making it easier to interact.

\section{CONCLUSION}

In this work were correlated well with NRTL model giving RMSD of $1.2 \%$ for tert-butanol sytems and $1.1 \%$ The result show that the capability of 1 octanol was better than that of tert-butanol as a solvent

Table 4. The energy of each compound calculated with Hyperchem Simulation.

\begin{tabular}{|c|c|c|c|c|}
\hline \multirow{2}{*}{ Data } & \multicolumn{4}{|c|}{ Compound } \\
\cline { 2 - 5 } & Eugenol & 1 -Octanol & Tert-butanol & Water \\
\hline $\begin{array}{c}\text { Total energy functional group } \\
\text { (kcal/mole) }\end{array}$ & 89.5723 & 4.7508 & 12.82 & 2.17 \\
\hline Dipole moment & 0.0000 & 0.9609 & 1.068 & 1.46 \\
\hline RMS gradient & 0.0819 & 0.0695 & 0.088 & 6.84 \\
\hline Steric effect (kcal/mole) & 139.1573 & 20.0175 & 28.80 & 7.47 \\
\hline
\end{tabular}


for eugenol. This is because octanol has a more nonpolar property compared with tert-butanol so the eugenol will be easier distributed with 1-octanol molecules than with tert-butanol molecules. For 1-octanol system, while UNIQUAC model giving RMSD 3.1\% for tertbutanol system and 4.3\% 1-octanol system.

\section{ACKNOWLEDGMENT}

The financial support from Ministry of Research, Technology and Higher Technology Republic of Indonesia under contract No: 484/PKS/ITS/2017, is gratefully acknowledged. The authors would like to thank to Lettizia Kris Harjanto and Maria Dominica Citta Nirmala Wibowo for their contribution in this experimental work.

\section{REFERENCES}

[1] Departemen Perindustrian 2008 Laporan Pengembangan Sektor Industri Tahun 2008 (Indonesia: Departemen Pertanian).

[2] Departmen Pertanian 2007 Revitalisasi Pertanian, Perikanan, dan Kehutanan (Indonesia:Departemen Pertanian)

[3] Julia L 1995 The Illustrated Encyclopedia of Essential Oils: The Complete Guide to the Use of Oils in Aromatherapy \& Herbalism Shaftesbury (Dorset: Element Books)

[4] Tagora B P S, Rinaldi S, Iriany 2002 Penentuan Kondisi Kesetimbangan Unit Leaching pada Produksi Eugenol dari Daun Cengkeh (Indonesia: Jurusan Teknik Kimia)

[5] Ketaren S 1985 Pengantar Teknologi Minyak dan Lemak Pangan (Indonesia: UI Press)

[6] Amparo C, J de la T, R Munoz, Marta B 2005 Liquid Liquid Equilibria of The Mixture Linalool + Ethanol + Water at Different Temperatures J. Fluid Phase Equilibria 238 72-76

[7] Retno K H S, Kuswandi, Gede W 2016 Ternary Liquid-Liquid Equilibrium for Eugenol + tertButanol + Water System at 303.15 and $323.15 \mathrm{~K}$ and Atmospheric Pressure (Indonesia: International Seminar on Fundamental and Application of Chemical Engineering AIP Conference Proceedings). 